Recepción: 15 / 04 / 2017

Aceptación: 01 / 05 / 2017

Publicación: 15 / 05 / 2017
Ciencias Administrativas

Revisión Sistemática

\title{
Las nuevas multinacionales de Asia
}

The new multinationals of Asia

As novas multinacionais da Ásia

Xavier F. Flores-Torres

xavier.florest@ug.edu.ec

Cynthia M. Legarda-Arreaga " cynthia.legardaa@ug.edu.ec

Grace E. Tello-Caicedo ${ }^{\text {"I }}$ grace.telloc@ug.edu.ec

Correspondencia: xavier.florest@ug.edu.ec 


\section{Resumen}

La realidad en el mundo, está reflejando los primeros indicios de lo que vendrá. Empresas de mercados emergentes que ganan terreno en mercados desarrollados, expandiendo sus raíces y transformándose en verdaderos referentes, marcas desconocidas hasta el momento, compitiendo mano a mano con las históricas, esto nos refleja la importancia a la que nos enfrentamos en un mundo cada vez más competitivo. No hay vuelta atrás. El nuevo escenario económico global muestra un cambio profundo en el mapa de las multinacionales, que cada vez tratan de ganar terreno en precio y calidad de sus productos, buscando ideas innovadoras para posicionarse en los mercados mundiales, y sobre todo que la expansión de la gran mayoría de estas se origina en el continente asiático y que brinda un campo de estudio interesante hacia empresas competitivas e innovadoras.

Palabras clave: Empresas; multinacionales; innovación; globalización. 


\begin{abstract}
The reality in the world is reflecting the first signs of what will come. Emerging market companies gaining ground in developed markets, expanding their roots and becoming true referents, brands unknown so far, competing hand in hand with historical ones, this reflects the importance we face in an increasingly world competitive. There is no way back. The new global economic scenario shows a profound change in the map of multinationals, who are increasingly trying to gain ground in price and quality of their products, looking for innovative ideas to position themselves in world markets, and above all that the expansion of the Most of these originate in the Asian continent and that provides an interesting field of study towards competitive and innovative companies.
\end{abstract}

Key words: Business; multinational companies; innovation; globalization. 


\section{Resumo}

A realidade no mundo, está refletindo os primeiros sinais de que está para vir. Empresas em mercados emergentes estão ganhando terreno nos mercados desenvolvidos, ampliando suas raízes e se tornando referências reais, marcas até então desconhecidos, competindo em estreita colaboração com o histórico, isto nos reflete a importância que enfrentamos em um mundo cada vez mais competitivo. Sem volta. O novo cenário econômico global mostra uma profunda mudança no mapa das multinacionais que cada vez mais procuram a ganhar terreno em preço e qualidade de seus produtos, à procura de ideias inovadoras para a posição nos mercados mundiais, e especialmente a expansão da grande a maioria destes se originou na Ásia e fornece um interessante campo de estudo para as empresas competitivas e inovadoras.

Palavras chave: Empresas; multinacionais; inovação; globalização. 


\section{Introducción.}

Los expertos pronostican un fenómeno creciente que desembocará en que, en 10 años, se verán "multis" emergentes comprando Las nuevas multinacionales La crisis económica mundial también impactó en el desarrollo de compañías globales provenientes de países emergentes. Por qué, en apenas dos años, el número de empresas de Brasil, Rusia, India y China con participación en mercados externos se multiplicó por cuatro. Cuáles son las claves por las que prevalecen ante las tradicionales multinacionales compañías ya "desarrolladas" o, en su defecto, la absorción de emergentes por parte de capitales multinacionales. Si se toma como referencia la lista de las 500 mayores empresas del mundo por capitalización bursátil (del informe 2009 de The Boston Consulting Group), a la cabeza del ranking se encuentra Petrochina (superó a la estadounidense Exxon), mientras que también son del mismo origen la primera compañía energética, la líder de telecomunicaciones (China Mobile) y el primer banco del mundo (ICBC) por valor en Bolsa. Es más, las multinacionales procedentes de economías emergentes ocupan la mitad de los primeros 10 puestos de la clasificación. (Martínez Legorreta, 2016)

De acuerdo con el estudio, que analiza los nuevos referentes globales, en apenas dos años, el número de empresas de Brasil, Rusia, India y China (los famosos BRIC) presentes se multiplicó por cuatro. Su participación resultó, además, decisiva para el auge de la inversión extranjera directa de los últimos años y para la ola de fusiones y adquisiciones "transfronterizas" previa a la crisis. "Estas economías crecen a tasas muy significativas desde la crisis asiática del '97', destaca Eduardo Fracchia, Economista y profesor del área de Economía del IAE, Bussiness School de Argentina. Liderados por el impacto de China, toda la región del sudeste asiático, América Latina y Europa del Este poseen firmas que están entrando en los rankings internacionales de ventas. "En diez años, la cuota para las compañías de naciones emergentes en el top 100 será del 25\%, contra el $15 \%$ de la 
actualidad. Es un proceso sin retorno asociado a la convergencia que estamos viviendo a escala internacional. Es un hecho evidente del avance de la globalización que no tiene vuelta atrás", agrega el experto. (Lascurain Fernández, 2012)

Lo que en los '80, con la irrupción de empresas coreanas (como Samsung o LG) parecía una curiosidad, fue tal el protagonismo que consiguieron que, en sólo diez años, ya habían logrado ubicarse entre las multinacionales más capitalizadas del mundo. Hoy, no caben dudas de que la tendencia llegó para quedarse.

Las compañías no pueden limitarse a sus mercados de origen, sino que deben tender a ser multinacionales, casi desde su nacimiento". Como los mercados desarrollados parecen haber perdido atractivo, a raíz de la crisis, el escenario económico global muestra otra cara. Mientras algunas compañías luchan por sobrevivir, afectadas por un contexto inestable, otras están preparadas para dar el zarpazo.

Todo eso hace que los mercados desarrollados no ofrezcan a las corporaciones alternativas para seguir creciendo, debido a que los consumidores están complicados”, analiza D’Andrea. En contrapartida, aparecen economías de países como China, India o Brasil, a las que se suman Sudáfrica, Israel, Corea, Australia y Nueva Zelanda, que, desde su óptica, se muestran con "mayor solidez, mejor tecnología y con un camino más estabilizado" como para ir por más. "En el caso de China, India y los países emergentes que se estabilizan y encuentran el camino, tienen años por delante. Aparece la clase media brasilera, que ya representa el 50\% del total. Son 100 millones de personas... No es poco", agrega. El avance no se detiene. China desplazó a los Estados Unidos como primer socio comercial de Las nuevas... Liderados por el impacto de China, toda la región del 
sudeste asiático, América Latina y Europa del Este poseen firmas que están entrando en los rankings internacionales de ventas. (Vázquez-Barquero, 2000)

Brasil, mientras que en Europa y Japón ya no alumbran grupos globales, como sucedía en otros tiempos. Y así, aparecen en escena casos de compañías que proceden de países que, años atrás, nunca hubiera imaginada que ganarían tanto terreno a escala global. Por eso, para Fracchia esto no es un hecho novedoso: "Se sabía que, desde los ’90, el mayor porcentaje de facturación de las multinacionales se daría en los emergentes". Al mismo tiempo, explica el fenómeno que se observa en la actualidad: "Lo que estamos viviendo es que empresas de los propios países se están ocupando de atender estos mercados y los de las naciones centrales. (Swan, 1956)

Existe, sin lugar a dudas, un nuevo escenario de los negocios que impulsó a las firmas de países emergentes a salir con agresividad al exterior". Barajar y dar de nuevo No sorprende que una de las ciudades con más multinacionales del planeta sea Pekín (la cuarta), incluso por encima de Nueva York. Tampoco extraña que el etanol brasileño haga funcionar muchos autos y aviones de todo el mundo, más allá de hacerlo en su propio mercado.

La realidad refleja este barajar y dar de nuevo que se da a escala global: empresas indias de tecnología (como Infosys o Wipro) se encuentran entre las mejores de su sector en el mundo, mientras que otras, como Reliance y Tata, salen en la clasificación de las compañías más innovadoras del planeta de la revista norteamericana Business Week, más de un millón de ciudadanos indios se suscribieron para adquirir el modelo Nano, de Tata. Los países emergentes, entre ellos los denominados "BRIC" (Brasil, Rusia, India y China), incrementan su incidencia tanto en el PBI como en el comercio mundial. "Es claro que la actividad de las multinacionales de estas naciones no es ajena a esta performance, y su desarrollo resulta crucial, además, para el nacimiento 
de nuevas empresas que, obviamente, van a llevar en su genética la impronta de lo global" D’Andrea no tiene dudas: “Las emergentes tienen para enseñarse entre sí, cómo atender mejor y dar servicios con valor agregado, de qué manera potenciar sus productos, para esos nuevos consumidores. Eso es lo que las grandes no piensan. Por eso, aparecerán las multinacionales emergentes. Serán las pioneras y no las multinacionales que ya conocemos, que están presas de otros paradigmas, de sus marcas e imagen, y de sus grandes costos” (Waterman, 1998)

\section{Pasos a Cumplir de las Multinacionales}

Claro que no cualquier empresa está en condiciones de transformarse en "global”. Hay pasos que debe cumplir una compañía para lograr ese objetivo. A saber:

1. capacidad de intuir los nuevos segmentos que crecen rápido, como el fenómeno de la clase media brasileña o el de China;

2. sensibilidad de las "locales" para adaptarse a los gustos que evolucionan;

3. la visión de los líderes tiene que ser sensible, precisamente, a las necesidades y la idiosincrasia de cada mercado en particular;

4. apertura conceptual que vaya más allá del negocio. Caballero hace su aporte: "La claves para que aparezcan este tipo de compañías son, por un lado, el crecimiento de los servicios dentro de la matriz de producción global, y el desarrollo de actividades 'sin fronteras' como las TIC, software, diseños especiales, etc. Para muchas actividades, que van incrementando su participación en el PBI global, ya no es necesario estar radicado en un mercado puntual. El lugar es la web y el mundo. Para otras actividades más 'tradicionales', es importante alcanzar muchos mercados para poder crecer”. 
Las claves para el éxito están centradas en avanzar en el proceso convencional de internacionalización de modo coherente. Primero a través de exportaciones, luego por medio de alianzas en los mercados externos y, finalmente, estas firmas crecen a través de inversión directa externa. (Fracchia)

Las empresas multinacionales tiene sus orígenes en países que no se encuentran entre los más avanzados del mundo desde los puntos de vista tecnológicos o de marca, estas proceden:

- De economías con nivel de ingresos medio-alto, como Corea del sur o Taiwán, España, Irlanda o Portugal.

- De economías emergentes como china o india, Brasil, Chile, México, Turquia.

- De países en vías de desarrollo como indonesia, Tailandia o Egipto

- De países ricos en petróleo, como los Emiratos Árabes Unidos, Nigeria, Rusia o Venezuela

Estas operan a nivel internacional y utilizan diferentes formas, desde alianzas y empresas conjuntas hasta subsidiarias de plena propiedad. Unas son pequeñas y están centradas en el producto otras son grandes y se diversifican en varias líneas del producto e incluso industrias.

Se han referido a ellas de varias maneras multinacionales del tercer mundo, empresas tardías, multinacionales emergentes, etc. Dependiendo de su región han sido etiquetadas para el caso de Asia se las conoce como “multinacionales dragón”.

Las nuevas multinacionales son actores importantes en los procesos de inversión directa en el exterior (IDE) y en las adquisiciones transfronterizas (UNCTAD 2008). A pesar que estas no cuentan con la mejor tecnología o habilidades comerciales en sus industrias. Se han repartido por el mundo utilizando fórmulas innovadoras 
Muchas de estas empresas eran competidores menores hace una década; hoy suponen un reto para muchas de las multinacionales más desarrolladas y mejor establecidas del mundo en gran variedad de industrias y mercados.

El auge de las nuevas multinacionales en especial de Corea del Sur, Taiwán o Singapur las cuales carecían de empresas de talla internacional y actualmente poseen algunas de las más grandes del mundo eran países en vías de desarrollo a principio de los años setenta. En treinta años se han transformados en economías industriales. También el sector de servicios ha tenido un rápido desarrollo en estos países hasta alcanzar niveles altos de competitividad homologables a los líderes del sector en ámbitos como la infraestructura y los servicios financieros.

Uno de los rasgos fascinantes del aumento de las nuevas multinacionales es la rapidez con que han crecido internacionalmente. Desde el 90 varios países y sus empresas han jugado un papel importante en la economía global no solo como exportadores sino como inversores directos en el extranjero. La IDE incluye las adquisiciones y la constitución de filiales en el exterior en las que el inversor mantiene al menos el $10 \%$ de acciones de la subsidiaria extranjera en la que invierte, el objetivo de la IDE es controlar la gestión de la compañía en la que se invierte.

La tabla siguiente muestra información sobre países emisores de IDE más importantes del mundo. Dejando de lado a Hong Kong y Países Bajos que son centros de inversión, comercio, y tránsito de capitales. Los líderes en IDE siguen siendo Usa, Reino Unido, Francia y Alemania pero otros nuevos países importantes en IDE son Rusia, (248 millardos o mil millones de dólares), Taiwán (181), Brasil (157), China (229), Corea del Sur (115), Malasia (75), India (77). 


\begin{tabular}{|l|l|l|l|l|l|l|}
\hline \multirow{2}{*}{ PAÍS } & \multicolumn{3}{l|}{ Stock de inversión en el exterior } & Número de \\
\cline { 2 - 5 } & \multicolumn{2}{|l|}{ Millardos de dólares } & \multicolumn{2}{l|}{ Porcentaje del PIB } & Empresas \\
& 1999 & 2009 & 1990 & 2009 & multinacionales \\
\hline BRASIL & 41 & 157,7 & 9,4 & 10 & 226 \\
RUSIA & $*$ & 248,9 & $*$ & 20,1 & $*$ \\
INDIA & 0,1 & 77,2 & $*$ & 6,1 & 815 \\
CHINA & 4,5 & 229,6 & 1,1 & 4,9 & 3429 \\
SINGAPUR & 7,8 & 213,1 & 21,2 & 120,3 & $*$ \\
HONG KONG & 11,9 & 834,1 & 15,5 & 396,1 & 1167 \\
TAIWAN & 30,4 & 181 & 18,4 & 47,8 & 606 \\
COREA & & & & & \\
SUR & 2,3 & 115,6 & 0,9 & 13,9 & 7460 \\
MALASIA & 0,8 & 75,6 & 1,7 & 39,5 & $*$ \\
JAPÓN & 201,4 & 740,9 & 6,7 & 14,6 & 4663 \\
ESTADOS & & & & & \\
UNIDOS & 731,8 & 4302,9 & 12,6 & 30,2 & 2418 \\
ALEMANIA & 151 & 1378,5 & 8,8 & 41,2 & 6115 \\
\hline
\end{tabular}

\section{Tabla $N^{\circ}$ 1.- Stock de inversión en el exterior por país}

Fuente: UNCTAD 2010

Las cifras de Singapur no solo recogen las inversiones de las compañías sino de aquellas que utiliza el país como una plataforma para la inversión y el comercio. A nivel global la participación de los países en vías de desarrollo en el stock de IDE emitida acumulada ha aumentado del 6,96\% en 1990 al 14,18\% en 2009 (UNCTAD 2010)

Una de las características importante de los países de origen de las nuevas multinacionales a excepción de Corea del Sur y Taiwán, no son líderes tecnológicos si se mide dicho liderazgo a través de sus patentes (Furman et al., 2002). En contraste muchos de estos países sobresalen por el gran número de certificados de calidad de gestión, en relación con el tamaño de sus economías sobre todo China, Taiwán y Malasia como mostramos en la siguiente tabla, los cuales muestran que estos países son eficaces y de talla mundial a la hora de implementar sus innovaciones con habilidades directivas y organizativas. 


\begin{tabular}{|c|c|c|c|c|c|}
\hline \multirow{2}{*}{ PAÍS } & \multirow[b]{2}{*}{$\begin{array}{l}\text { PIB } \\
\text { Millardos } \\
\text { de } \\
\text { Dólares }\end{array}$} & \multicolumn{2}{|l|}{ Patentes } & \multicolumn{2}{|c|}{ Certificados ISO } \\
\hline & & Número & $\begin{array}{l}\text { Por } \\
\text { millardo } \\
\text { de PIB }\end{array}$ & Número & $\begin{array}{l}\text { Por millardo } \\
\text { de PIB }\end{array}$ \\
\hline BRASIL & 2020,1 & 2358 & 1,2 & 14539 & 7,2 \\
\hline RUSIA & 2687,3 & 2660 & 1 & 16051 & 6 \\
\hline INDIA & 3783,6 & 4802 & 1,3 & 37958 & 10 \\
\hline CHINA & 9104,2 & 9492 & 1 & 224616 & 24,7 \\
\hline SINGAPUR & 252,9 & 4959 & 19,6 & 4526 & 17,9 \\
\hline HONG KONG & 307,2 & 9862 & 32,1 & 3499 & 11,4 \\
\hline TAIWÁN & 379 & 94579 & 249,5 & $*$ & $*$ \\
\hline $\begin{array}{l}\text { COREA DEL } \\
\text { SUR }\end{array}$ & 1324,4 & 72332 & 54,6 & 23036 & 17,4 \\
\hline MALASIA & 384 & 1298 & 3,4 & 6267 & 16,3 \\
\hline $\begin{array}{l}\text { JAPÓN } \\
\text { ESTADOS }\end{array}$ & 4138,5 & 756795 & 182,9 & 62746 & 15,2 \\
\hline UNIDOS & 14256,3 & 2191092 & 153,7 & 32400 & 2,3 \\
\hline ALEMANIA & 2984,4 & 272055 & 91,2 & 48324 & 16,2 \\
\hline
\end{tabular}

\section{Tabla $N^{\circ}$ 2.- Patentes registrados por país}

Fuente: oficina de patentes y marcas registradas estadounidenses; organización internacional para la estandarización.

La siguiente tabla muestra las mayores nuevas multinacionales no financieras en términos de activos extranjeros se puede observar que estas empresas operan en gran variedad de sectores que van desde petróleo y minería hasta cemento y químicas, pasando por automóviles y electrónica y varios de infraestructuras como electricidad, transportes y telecomunicaciones. 
Xavier F. Flores-Torres; Cynthia M. Legarda-Arreaga; Grace E. Tello-Caicedo

\begin{tabular}{|c|c|c|c|c|c|}
\hline Empresa & País & Sector & $\begin{array}{l}\text { Activos en el } \\
\text { extranjero } \\
\text { (Millardos } \\
\text { dólares) }\end{array}$ & \begin{tabular}{l}
\multicolumn{1}{c|}{ Ventas } \\
totales \\
( Millardos de \\
dólares)
\end{tabular} & $\begin{array}{l}\text { Número de } \\
\text { filiales } \\
\text { en el } \\
\text { exterior }\end{array}$ \\
\hline Telefónica & España & Telecomunicaciones & 101,9 & 66,4 & 165 \\
\hline Hutchinson & Hong & Diversificada & & & \\
\hline Whampoa & Kong & $*$ & 70,7 & 34,4 & 115 \\
\hline Grupo & & & & & \\
\hline $\begin{array}{l}\text { Ferrovial } \\
\text { Repsol }\end{array}$ & España & Infraestructuras & 60,2 & 9,1 & \\
\hline YPF & España & Petróleo & 38,3 & 64,4 & 71 \\
\hline Endesa & España & Electricidad & 31,4 & 25,8 & 65 \\
\hline Petronas & Malasia & Petróleo & 30,7 & 51 & 4 \\
\hline Samsung & Corea del & & & & \\
\hline Electronics & Sur & Electrónica & 27 & 91,9 & 78 \\
\hline Cemex & México & $\begin{array}{l}\text { Cementos } \\
\text { Material de }\end{array}$ & 24,4 & 18,1 & 493 \\
\hline $\mathrm{CRH}$ & Irlanda & Construcción & 22,9 & 23,5 & 514 \\
\hline Hyundai & Corea del & & & & \\
\hline Motor & Sur & Automóvil & 19,6 & 68,5 & 19 \\
\hline $\begin{array}{l}\text { Singtel } \\
\text { CITIC }\end{array}$ & Singapur & $\begin{array}{l}\text { Telecomunicaciones } \\
\text { Diversificada }\end{array}$ & 18,7 & 8,6 & 103 \\
\hline Group & China & $*$ & 17,6 & 10,1 & 12 \\
\hline Formosa Plastic & & & & & \\
\hline Group & Taiwán & Químico & 16,8 & 50,4 & 11 \\
\hline Jardine & Hong & Diversificada & & & \\
\hline $\begin{array}{l}\text { Matheson } \\
\text { LG }\end{array}$ & Kong & $*$ & 16,7 & 16,3 & 108 \\
\hline Corporatio & Corea del & & & & \\
\hline $\mathrm{n}$ & Sur & Electrónica & 15 & 70,6 & 3 \\
\hline CVRD & Brasil & Minería & 15 & 46,7 & 17 \\
\hline
\end{tabular}

Tabla $N^{\circ}$ 3.- Nuevas multinacionales no financieras en activos extranjeros

Fuente: UNCTAD 2008

Otra forma de ilustrar la distribución nacional de las nuevas multinacionales es analizando el Global Fortune 500 de las empresas más grandes del mundo en términos de ingresos. China, Corea del Sur y España encabezan la clasificación (tabla siguiente) aunque definen y miden la demografía de las nuevas multinacionales de diferentes formas, estas clasificaciones indican sin lugar a dudas 
que la economía global ésta cada vez más integrada por empresas con sede en países a los que pocos asociarían con niveles de desarrollo tecnológico o de marcas reconocidas mundialmente.

Las nuevas multinacionales, en el Ranking por país revista Fortune: se basa en la facturación total durante 2009.

\begin{tabular}{|l|l|}
\hline PAÍS & Número de empresas \\
\hline CHINA & 46 \\
COREA DEL & \\
SUR & 10 \\
ESPANAA & 10 \\
INDIA & 8 \\
TAIWAN & 8 \\
BRASIL & 7 \\
MEXICO & 2 \\
RUSIA & 6 \\
IRLANDA & 1 \\
MALASIA & 1 \\
POLONIA & 1 \\
ARABIA SAUDI & 2 \\
SINGAPUR & 1 \\
TAILANDIA & \\
\hline
\end{tabular}

\section{Tabla $N^{\circ}$ 4.- Nuevas multinacionales Ranking por país}

Fuente: Revista fortune 2009

Las primeras nuevas multinacionales surgen de los llamados tigres asiáticos que se industrializaron durante los años setenta (Haggard 1990). Taiwán un país que destaca tanto por su tecnología como por su innovación, ha demostrado ser el terreno más fértil para el desarrollo de empresas inversoras en el exterior, entre las que se encuentran la matriz de Formosa plastics, Taiwán semiconductor y ACER. Siguiendo una trayectoria de desarrollo más orientada a la industria a gran escala. 
Corea del Sur es el país de origen de algunas de las industrias más conocidas en electrónica y en electrodomésticos (Samsung y LG) y en automóviles (Hyundai y KIA).

La ciudad estado Singapur ha generado multinacionales en los sectores de alimentación y bebidas (Fraser y neave, want want), electrónico (OLAM), telecomunicaciones (Singtel), inmobiliario (CapitaLand), transporte (Neptune Orient Lines) y hotelero (City Developments).

Por su parte Hong Kong es la sede de un gran número de multinacionales, encabezadas por Hutchinson Whampoa, la mayor compañía portuaria del mundo.

Más recientemente, las nuevas multinacionales de los países del bloque denominado el acrónimo Bric (Brasil, Rusia, India y China) han realizado grandes avances en la economía global. India cuenta con empresas en posiciones prominentes no solo en sectores tecnológicos y de servicios externos (como Infosys, Tata consultancy services o Wipro) sino también como en otros sectores como el siderúrgico, el de automoción y el farmacéutico. Las empresas chinas han irrumpido con fuerza en los mercados globales no solo como exportadoras sino también como inversoras en el exterior y lo han hecho en gran cantidad de industrias desde minería y petróleo hasta química y siderúrgica. En electrodomésticos y electrónica. China cuenta con tres empresas cada vez más conocidas como Haier, Lenovo y huawei. 


\begin{tabular}{|l|c|c|c|}
\hline Empresa & País & Sector & Posición en el mercado global \\
\hline POSCO & $\begin{array}{c}\text { Corea } \\
\text { del Sur }\end{array}$ & Siderurgia & $4^{\circ}$ EN ACERO \\
$\begin{array}{l}\text { Bharat } \\
\text { Forge }\end{array}$ & India & Metales & \\
ACER & Taiwán & Ordenador & $2^{\circ}$ EN FORJA \\
Lenovo & China & Ordenador & $3^{\circ}$ MARCA DE ORDENADOR \\
BYD & China & Electrónica & $4^{\circ}$ MARCA DE ORDENADOR \\
Infosys & India & $\begin{array}{c}\text { Servicios de } \\
\text { información }\end{array}$ & $1^{\text {o }}$ BATERIAS DE NIQUEL-CADMIO \\
TCS & India & información & TOP 5 SERVICIOS DE \\
Samsung & Corea & Electrónica de & TOP 5 SERVICIOS DE \\
electronics & del Sur & consumo & INFORMACIÓN \\
Wipro & India & Servicios externos & TOP 5 SERVICIOS EXTERNOS \\
\hline
\end{tabular}

Tabla $N^{\circ}$ 5.- Las nuevas multinacionales con las posiciones más relevantes en el mercado global al final de 2008

Fuente: compilación de Mauro Guillen de varias fuentes

Las Multinacionales tradicionales y las nuevas

El modelo tradicional de la empresa multinacional, caracterizado por la inversión directa en el exterior (IDE) con el objeto de aprovechar las capacidades específicas de la empresa desarrolladas en el país de origen y un enfoque paulatino de internacionalización, país por país, domino dominó la economía global durante gran parte del siglo XX el cual tuvo su origen en la revolución industrial de finales de siglo XIX. El punto culminante de su expansión mundial se alcanzó en los años sesenta y principios de los setenta, cuando las barreras al comercio y a la inversión desaparecieron gradualmente en todo el mundo (Chandler, 1990; Wilkings, 1974; Kindleberger, 1969; Vernon 1979). 
Aunque en aquel momento ya se documentaron variaciones significativas en la estrategia y en la estructura de las multinacionales norteamericanas y europeas (Stopford y Wells, 1972), y el auge de las multinacionales japonesas durante los años setenta y ochenta añadió aún más diversidad al universo de las corporaciones multinacionales (Kenney y Florida, 1993).

Las empresas de los países ricos y tecnológicamente avanzados tenían en común una seria de características. Entre ellas destacaban sus fortalezas tecnológicas, de marketing y directivas, que les permitieron superar las llamadas desventajas del extranjero en diversos mercados, invirtiendo en mayor parte en subsidiarias de plena propiedad o de propiedad mayoritaria, transfiriendo tecnología, productos y experiencia desde sus oficinas centrales hasta las operaciones más remotas repartidas por todo el mundo y estableciendo controles burocráticos y financieros.

Sin embargo, en las dos últimas décadas las nuevas multinacionales de países emergentes, de ingresos medio-altos o ricos en petróleo han seguido modelos totalmente diferentes de expansión internacional. El inesperado aumento de importancia de empresas como Haier de China, Tata Consultancy Services de India o Embraer de Brasil.

\section{La Teoría de la empresa multinacional}

Aunque las empresas multinacionales han existido desde hace mucho tiempo, los investigadores no intentaron entender la naturaleza y los factores determinantes de sus actividades transfronterizas hasta la década de los cincuenta del siglo pasado.

"El control de la empresa extranjera se desea para acabar con la competencia entre aquella empresa extranjera y las empresas en otros países o el control se desea para apropiarse de la totalidad de los rendimientos de determinadas habilidades y capacidades" (Hymer, 1962). La 
aportación fundamental de Hymer fue que las empresas multinacionales poseen cierto tipo de ventajas propias que las diferencian de las empresas meramente nacionales, ayudándoles de esta forma a superar la desventaja del extranjero.

Las multinacionales existen porque ciertas condiciones económicas y ventajas propias hacen que sea conveniente y posible para ellas realizar de manera rentable la producción de un bien o de un servicio en un emplazamiento en el extranjero. Es importante distinguir entre la expansión vertical y la horizontal en el exterior para entender completamente los principios económicos básicos que subyacen en las actividades de las empresas multinacionales en general y de las nuevas multinacionales en particular. La expansión vertical se produce cuando la empresa sitúa bienes o empleados en un país extranjero con el propósito de asegurar la producción de una materia prima, un componente o un insumo (expansión vertical hacia atrás) o la distribución y venta de un bien o servicio (expansión vertical hacía delante). La condición necesaria para que una empresa se expanda verticalmente es la existencia de una ventaja comparativa en el emplazamiento en el exterior. Típicamente la ventaja tiene que ver con los precios o con los rendimientos de factores de producción como capital, trabajo o tierra.

La expansión horizontal ocurre cuando la empresa establece una planta de producción o una instalación de distribución en un emplazamiento en el extranjero con el objetivo de vender en ese mercado y sin abandonar la producción de bienes o servicios en el país de origen.

La decisión de expandirse horizontalmente se rige por factores distintos de aquellos que determinan la expansión vertical. La producción de un bien o un servicio en un mercado exterior es aconsejable cuando existen barreras proteccionistas, altos costes de transporte, tipos de cambio de 
moneda desfavorables o una necesidad imperiosa para la adaptación a las peculiaridades de la demanda local que hacen que la exportación desde el país de origen sea inviable o no rentable.

Los investigadores en el campo de la gestión internacional también han reconocido que las empresas que poseen las ventajas competitivas necesarias no se convierten en multinacionales de la noche a la mañana, sino de forma gradual, pasando por diferentes etapas

\section{Las nuevas multinacionales entran en escena}

Los primeros investigadores del fenómeno de las empresas multinacionales de los países en vías de desarrollo, recientemente industrializados, emergentes, o de renta medio-altas, centraron su atención en las inversiones verticales como horizontales llevadas a cabo por estas empresas.

Las inversiones verticales, después de todo, son fácilmente justificables en términos del deseo de reducir la incertidumbre y minimizar el oportunismo cuando se necesitan inversiones en activos específicos, tanto si la empresa procede de un país desarrollado como si no.

Las inversiones horizontales de las nuevas multinacionales, no obstante, son más arduas de explicar porque se supone que son llevadas a cabo por la posesión de activos intangibles, y las empresas de países en vías de desarrollo no se espera que los posean, al menos la misma clase de activos intangibles que las multinacionales ya establecidas procedentes de los países ricos.

Las nuevas multinacionales de los ochenta y los noventa pretenden convertirse en líderes mundiales en sus respectivos sectores, dejando de ser jugadores marginales (Mathews 2006). Además las nuevas empresas multinacionales no proceden solo de países emergentes. Algunas empresas catalogadas como empresas nacidas globales (born-globals) o renacidas globales (bornagain born-globals) (Bell, Mcnaughton y Young, 2001: Rialp et al,.2005) han surgido de países 
desarrollados siguiendo trayectorias aceleradas de internacionalización que desafían la visión gradual de la expansión internacional.

Las principales características de las nuevas multinacionales comparándolas con las tradicionales aparecen en la tabla siguiente, las dimensiones de esta realizan las diferencias clave entre las multinacionales nuevas y las convencionales. Lo que más llama la atención es el ritmo acelerado de la internacionalización de las nuevas multinacionales, a medida que han intentado reducir la distancia entre su cobertura de mercado y la presencia global de las empresas multinacionales de los países más desarrollados (Matthews 2006).

La segunda característica de las nuevas multinacionales es que, independientemente del país de origen, han estado obligados a superar no solo la desventaja del extranjero, sino también la desventaja de ser recién llegados a la escena internacional y carecer, por tanto, de los recursos y de las capacidades de las multinacionales establecidas de los países más avanzados. Por esta razón, la expansión internacional de las nuevas multinacionales corre en paralelo al proceso de mejora y actualización de capacidades a través del cual los recién llegados buscan el acceso a recursos y capacidades externas para ponerse al nivel de sus competidores más avanzados, reduciendo su diferencial de competitividad con respecto a las multinacionales establecidas (Matthews, 2006; Aulakh, 2007; Li, 2007). No obstante, a pesar de carecer de una dotación de recursos equivalente a los de las empresas multinacionales de los países desarrollados, las nuevas multinacionales tienen, normalmente, una ventaja sobre ellas, y que es que tienden a poseer unas capacidades políticas más fuertes. Como las nuevas multinacionales están más acostumbradas a relacionarse con gobiernos discrecionales y/o inestables de sus países de origen están mejor preparadas que las multinacionales tradicionales para triunfar en países extranjeros caracterizados por un entorno institucional débil 


\begin{tabular}{|c|c|c|}
\hline Dimensión & $\begin{array}{c}\text { Nuevas } \\
\text { multinacionales }\end{array}$ & Multinacionales tradicionales \\
\hline $\begin{array}{c}\text { Velocidad del } \\
\text { proceso } \\
\text { de } \\
\text { internacionalización }\end{array}$ & Acelerada & Desarrollo gradual \\
\hline $\begin{array}{l}\text { Ventajas } \\
\text { competitivas }\end{array}$ & $\begin{array}{l}\text { Débiles: desarrollo de recursos } \\
\text { requeridos }\end{array}$ & $\begin{array}{c}\text { Fuertes: los recursos necesarios } \\
\text { están } \\
\text { disponibles } \\
\text { internamente }\end{array}$ \\
\hline $\begin{array}{c}\text { Capacidades } \\
\text { políticas }\end{array}$ & $\begin{array}{c}\text { Fuertes: empresas acostumbradas a } \\
\text { entornos políticos inestables }\end{array}$ & $\begin{array}{l}\text { Débiles: empresas acostumbradas } \\
\text { a } \\
\text { entornos políticos } \\
\text { estables }\end{array}$ \\
\hline $\begin{array}{l}\text { Trayectoria de } \\
\text { expansión }\end{array}$ & $\begin{array}{c}\text { Trayectoria dual: entrada en países } \\
\text { emergentes para acceder a sus } \\
\text { mercados } \\
\text { y en países } \\
\text { desarrollados } \\
\text { para desarrollar y renovar sus } \\
\text { capacidades }\end{array}$ & $\begin{array}{l}\text { Trayectoria sencilla: } \\
\text { de países más cercanos a más } \\
\text { distantes }\end{array}$ \\
\hline $\begin{array}{l}\text { Modos de entrada } \\
\text { preferidos }\end{array}$ & $\begin{array}{l}\text { Crecimiento externo: alianzas, } \\
\text { empresas } \\
\text { conjuntas y } \\
\text { adquisiciones } \\
\end{array}$ & $\begin{array}{l}\text { Desarrollo interno: } \\
\text { filiales } \\
\text { de plena propiedad }\end{array}$ \\
\hline $\begin{array}{l}\text { Adaptabilidad } \\
\text { organizadora }\end{array}$ & $\begin{array}{l}\text { Alta, debido a su reciente y } \\
\text { relativamente } \\
\text { limitada presencial internacional }\end{array}$ & $\begin{array}{l}\text { Baja, debido a sus arraigadas } \\
\text { estructura } \\
\text { y cultura } \\
\text { organizativas. }\end{array}$ \\
\hline
\end{tabular}

\section{Tabla $N^{\circ}$ 6.- Nuevas multinacionales vs Tradicionales \\ Fuente: Las nuevas multinacionales (Guillen)}

Teniendo en cuenta la alta tasa de crecimiento de los países emergentes y su peculiar ambiente institucional, las capacidades políticas han sido especialmente valiosas para las nuevas multinacionales. 
Estas tres primeras características llevan a otras características clave de las nuevas multinacionales: su trayectoria dual en la expansión internacional. Las nuevas multinacionales se enfrentan a un dilema importante en su expansión internacional porque necesitan equilibrar el deseo de una mayor cobertura global de mercado con la necesidad de aumentar sus capacidades. Pueden usar fácilmente sus ventajas competitivas acumuladas en el país de origen en otros países emergentes o en vías de desarrollo, pero deben también entrar en países más avanzados para exponerse a la demanda más exigente y desarrollar así sus capacidades

Las nuevas multinacionales comienzan a invertir más en los países desarrollados para posicionarse en los mercados de esos países, aunque también realizan adquisiciones en ellos para asegurarse activos estratégicos, como tecnología o marcas.

Una quinta característica de las nuevas multinacionales es su preferencia por participar en procesos basados en crecimiento externo, en donde estas empresas utilizan simultáneamente las alianzas globales y las adquisiciones para superar las desventajas del extranjero en el país del socio/objetivo y conseguir acceder a sus ventajas competitivas, con el propósito de aumentar sus propios recursos y capacidades.

Una última característica de las nuevas multinacionales es que disfrutan de más libertad para implementar las innovaciones organizativas para adaptarse a los requisitos de la globalización, al no adolecer de limitaciones típicas de las multinacionales establecidas. Como consecuencia de su larga tradición y las peculiaridades de su desarrollo, muchas multinacionales de las economías desarrolladas sufren la fuerza de la inercia y la dependencia de la trayectoria seguida, que se manifiesta en la dificultad para cambiar sus profundos valores arraigados, su cultura y su estructura organizativa. (Matthews, 2006), señala que las nuevas multinacionales de Asia han adoptado una 
seria de formas organizativas innovadoras que se adaptan a sus necesidades, incluyendo estructuras de red y descentralizadas.

\section{Las grandes empresas coreanas}

El país coreano vive cada día que pasa más arraigado a nuestras costumbres y no nos damos cuenta. No es la primera vez que se escucha “esta empresa es coreana”. Pero si, resulta que hay más de las que pensábamos. Grandes empresas que se mueven con grandes cantidades de capital, grandes transnacionales que conviven en el día a día algunas de ellas.

Una cosa común a varias de ellas es que se suele asociar una marca a un solo producto. Así damos un ejemplo si preguntamos ¿qué fabrica Hyundai? Responderemos autos pero si vamos a Corea nos fijaremos en que esta empresa no solo fabrica automóviles sino también barcos y centros comerciales.

Esto se debe a que las empresas en Corea su gran mayoría son Chaebol, grandes empresas que controlan sectores de producción muy diversos, controlados mayormente de forma familiar. A continuación mostramos las transnacionales más importantes de este país asiático:

\section{Samsung}

Nosotros conocemos la filial Samsung Electronics, y sobretodo Samsung Mobile. Para nosotros Samsung son teléfonos móviles, televisores y productos de imagen y sonido, cámaras de fotos, ordenadores portátiles, monitores, impresoras, discos duros y otros elementos informáticos, aspiradoras, lavadoras, frigoríficos y otros electrodomésticos. 


\section{$L G$}

De esta empresa conocemos sus secciones LG Electronics y LG Mobile. Seguramente muchos tengáis un aire acondicionado de LG, o teléfonos móviles, televisores, portátiles, frigoríficos, lavadoras, aspiradoras, microondas, etc. Sin ir más lejos yo tengo un móvil de Samsung y Jumi tiene uno de LG.

\section{Hyundai}

Conocemos a Hyundai por sus coches, tanto turismos, todoterrenos, monovolúmenes o comerciales. Curiosamente he encontrado una web de Hyundai Electronics en España, aunque yo no la conocía.

\section{Daewoo}

Es también una empresa que conocemos por sus automóviles y por sus aparatos electrónicos. Pero una quiebra en la empresa hizo que ambas subdivisiones caminaran por sendas diferentes aunque ambos mantuvieron el nombre de Daewoo. Sobre todo en Daewoo Electronics, que se dedica a productos electrónicos como aires acondicionados, frigoríficos, lavadoras, televisores, etc. En cambio Daewoo Motors ha pasado en Europa a manos de General Motors, así pues el Daewoo Matiz, se ha quedado en un Chevrolet Matiz.

\section{Hanjin}

La gente de a pie habremos leido alguna vez "Hanjin" en algunos contenedores de trailers y camiones o -si vivimos cerca de una zona portuaria- en algunos de los contenedores que llegan vía 
marítima. Hanjin es una empresa que se dedica a la logística global, y lo que a la mayoría de nosotros nos llega son las imágenes de los contenedores comerciales.

\section{Hankook}

Es otra de esas empresas que se dedica a varias cosas pero que nosotros conocemos por sus neumáticos. Bajo el nombre de Hankook Tire, la empresa surcoreana se dedica a la producción de neumáticos para turismos, camiones, carreras, etc.

\section{Kia}

Es otra de las empresas automovilísticas que tenemos en España. Kia Rio, Soul, Picanto, son algunos de los muchos vehículos Kia con los que estamos familiarizados. Pertenece al grupo Hyundai Kia Motors desde 1998 año en que Hyundai compró el 51\% de la empresa.

\section{Ssangyong}

Es otra empresa de automóviles. Especialmente en España veremos automóviles estilo todoterreno como los Actyon, Kyron o Rodius, que son algunos de sus modelos.

\section{Korean Air y Asian Airlines}

Son dos empresas de aerolineas coreanas. Sólo las conoceremos directamente en España en caso de ofrecer algún vuelo directo España-Corea operado por alguna de ellas (Creo que de sólo Korean Air lo hace). Sin embargo es probable que si viajamos a Corea y hacemos trasbordo en algún aeropuerto internacional, el vuelo hasta Seúl sea operado por alguna de estas compañías, aunque hay muchas compañías no coreanas como Lufthansa, Finnair o Air France que hacen los mismos servicios. 


\section{Corporaciones Japonesas Multinacionales}

Antes de la Segunda Guerra Mundial, Japón era un país insular y aislado que estaba cerrado de muchas maneras al mundo. Después del daño extremo infligido en Japón en 1945 Japón comenzó un período de modernización y expansión industrial que ha visto su influencia económica expandirse alrededor del globo. Tomar el modelo de las compañías y corporaciones occidentales y adaptarlo a una versión japonesa única ha visto a las compañías japonesas convertirse en nombres establecidos internacionalmente.

\section{Automóviles}

En el área de la producción automotriz Japón se ha convertido en un gigante global. Las corporaciones multinacionales japonesas importantes que fabrican automóviles o que ofrecen partes y servicios automotrices son Toyota, Honda, Nissan, Mazda, Suzuki, Denso, Bridgestone y Aisin Seiki. Los autos japoneses son conocidos por su eficiencia en consumo de combustible y alto nivel de calidad. El mayor productor automotriz es Toyota Motor Company. De hecho, es una de las 10 mejores compañías multinacionales con base en ingresos anuales al momento de esta publicación.

\section{Electrónica}

Japón es casi sinónimo de la excelencia y el rendimiento en electrónicos de consumo. Muchos desarrollos líderes de la industria en este campo han venido de Japón y las compañías japonesas dominan muchos sectores de este mercado. Los jugadores multinacionales japoneses líderes en esta categoría son Panasonic, Sony, Toshiba, Hitachi, Sanyo, Matsushita, Sharp, Mitsubishi y Sumitomo. 


\section{Computadora y tecnología}

Al igual que con los bienes electrónicos de consumo, Japón ha mostrado una capacidad increíble para la innovación en el campo de las tecnologías de computación y asociadas. Las compañías como Canon, Sony, NEC, Ricoh y Fujitsu son marcas líderes a lo largo del mundo y llegan a la lista de Fortune 500 de las multinacionales líderes.

\section{Ingeniería y construcción}

Después de que la destrucción provocada por la Segunda Guerra Mundial, Japón se sometió a un período enorme de reconstrucción durante el cual muchos ingenieros japoneses y firmas de construcción se elevaron al dominio internacional. Una falta de recursos naturales y un mercado nacional relativamente pequeño ha forzado a las compañías japonesas en este campo para innovar y expandirse. Algunos de los nombres líderes en la industria japonesa en este sector internacionalmente son Takenaka, Shimizu, Kajima, Obeyashi, Komatsu, Taisei, Nippon Steel y Kobe Steel.

Por otro lado, las inundaciones de Tailandia, que por sus bajos costes y su situación geográfica se ha convertido en una de las principales fábricas de la región para las firmas niponas, han provocado un fuerte frenazo en la producción de muchas empresas y de sus proveedores, que, en muchos casos, ni siquiera se habían repuesto del todo de las nefastas consecuencias que supuso el terremoto, y posterior tsunami, que sacudió Japón en marzo de 2011 y que deprimió la economía nipona durante varios meses.

El impacto negativo en las exportaciones por la fortaleza del yen y el parón en la producción de las diez plantas que Toshiba posee en Tailandia (la mitad todavía ni siquiera han reanudado la 
actividad o no están a pleno rendimiento) han empujado a la empresa a rebajar su estimación anual de beneficios de 140.000 millones de yenes a 65.000 millones (650 millones de euros). Según la firma, estos dos factores reducirán en 80.000 millones de yenes el resultado operativo previsto, que caerá hasta 200.000 millones.

Por último, Canon, el mayor fabricante mundial de cámaras fotográficas, lanzó un 'profit warning' debido a la fortaleza de la divisa japonesa y la debilidad de la demanda, especialmente en Europa. La firma espera que sus ganancias anuales no crezcan más del $1 \%$.

\section{Taiwán}

Taiwán ofrece una serie de ventajas a las empresas multinacionales y a los inversores sobre otros países en Asia. La economía de Taiwán ha pasado de ser intensiva en mano de obra a estar basada en el conocimiento y el uso intensivo de capital, por ello hay una variedad de nuevas oportunidades de Inversión Extranjera Directa (IED) en Taiwán. De hecho, algunas de las principales industrias de alta tecnología del mundo se encuentran en Taiwán. Existen importantes oportunidades de negocios en:

\section{- Semiconductores}

- Opto-Electrónica

- Maquinaria de Precisión e Instrumentación

- Metales

- ordenadores y equipo de comunicación

- Productos Eléctricos

- Aviación y automoción

- Biomédica y productos de exportación farmacéutico 
HTC Corp.

Produce aparatos de telefonía móvil. Fue fundada en 1997 por Cher Wang. HTC tiene su sede en Taiwán; trabajan 8.948 trabajadores. Tiene centros de ventas y de servicio en Europa, América y Asia. HTC mantiene una presencia en todos los mercados clave, incluyendo los Estados Unidos, el Reino Unido, Alemania, Rusia, Singapur, Tailandia, Filipinas, Indonesia, India, Malasia, Australia, los Emiratos Árabes Unidos (EAU) y Brasil.

Acer

La estrategia de marca del Grupo Acer está estructurada en una familia de 4 marcas: Acer, Gateway, Packard Bell y eMachines. Esta estrategia multi-marca única permite que cada marca ofrezca un conjunto único de características. Acer es el $2^{\circ}$ productor mundial de portátiles. Tiene una plantilla de 7.000 trabajadores. En 2009 los ingresos fueron de 17.900 millones USD.

\section{Otras empresas taiwanesas importantes}

CPC (Chinese Petroleum Corp), Taiwan Power Co, Asus, TSMC Taiwan Semiconductor Manufacturing Company Ltd, Tatung Co., Qisda ex-BenQ Corp, Shin Kong Life Insurance Co., Taiwan Tobacco \& Wine Board,United Microelectronics Corp, AU Optronics Corp., China Steel, Uni-President Enterprises Corp., China Airlines, Eva Airways, Formosa Plastics Corp., Winbond Electronic Corp., Sampo Co Ltd, 


\section{Los Nuevos Gigantes Chinos}

\section{Haier}

La primera multinacional china de productos de consumo nació en 1984 en la ciudad costera de Qingdao, en el norte del país. La historia empezó cuando su fundador y actual presidente, Zhang Ruimin, 55 años, un dirigente del partido comunista chino, se hizo con una pequeña fábrica de frigoríficos en quiebra, en la que impuso un estilo de gestión occidental, basado en la productividad y la calidad. Ruimin, sobre el que hicieron hace poco una película, logró sacar la empresa de números rojos ya al año siguiente y convertirla en líder en su país en 1991. El crecimiento de la empresa \pm una sociedad semipública participada por capitales privados \pm fue espectacular a lo largo de los años Clara apuesta por la marca al contrario de otras empresas chinas, Haier ha optado por una estrategia de marca (lo que no impide que fabrique por subcontratación para diversas empresas occidentales) y por adaptar sus productos a los distintos mercados. Su línea para países europeos, creada en 2000, es diferente de la que vende en China. Está presente en 165 países, tiene 62 fábricas (22 fuera de China, una en EE UU), 96 líneas de productos y 15.000 referencias.

\section{Lenovo}

Empresa semipública, con sede en Beijing, primer fabricante chino de ordenadores, con una capacidad total de cinco millones de unidades anuales. Una vez integrada la división de PC de IBM, Lenovo ocupará la tercera posición mundial, con una cuota de mercado del $8 \%$ y una facturación de 12.000 millones de dólares. Además, de ordenadores produce servidores, terminales de móviles y periféricos. El nuevo gigante tiene una cultura muy adquisitiva. En tiempos, estudió una posible alianza con Time Warner en el negocio de Internet. También fue citada como posible compradora de 
las empresas conjuntas de PC Fujitsu-Siemens. Igual que Huawei, Lenovo, cotiza en las Bolsas de Hong Kong y Nueva York.

ZTE

Una de las tres grandes de los equipos de telecomunicaciones en China, ZTE es una empresa semipública fundada por nueve organismos chinos en 1985, que cotiza en Bolsa con un free float (acciones que cotizan libremente) del 38\% de su capital. Con sus productos redes para fijo, móvil, Internet o fibra óptica desplegados en más de 40 países, especialmente emergentes, ZTE facturó 1.900 millones de euros en 2003, de los que 605 fueron obtenidos fuera de China. Y espera multiplicar sus exportaciones por tres de aquí al año 2006. Ganadora del contrato de ADSL en los Juegos Olímpicos de Atenas, ZTE prepara su desembarco en Europa Occidental. Multiplicó su facturación por diez de 970 a 9.700 millones de euros entre 1993 y 2003. Se espera que en los próximos cinco años se coloque en los 20.000 millones de euros. La sede de la empresa en Qingdao es una auténtica metrópoli, repleta de edificios de vanguardia, y en la que trabajan más de 15.000 personas.

\section{Huawei}

Esta empresa de Shenzhen, fundada en 1988, se lanzó al mercado mundial en 2000, con lo que ha logrado elevar sus ventas desde 2.700 millones de dólares de 2002 a los 5.000 millones previstos para 2004. Dedica el 11\% de su facturación a I+D un 46\% de sus 22.000 empleados (3.000 en el extranjero), está implicado en labores de Investigación. Mantiene 11 institutos de I+D, seis en China y cinco en el exterior. Entre sus clientes se cuentan algunas de las principales operadoras del mundo, desde BT a Telefónica, pasando por la holandesa Telfort y la estadounidense NTCH. Según 
la consultora Gartner Group, ya es el segundo proveedor del mundo en ADSL (con 17\% de cuota de mercado), por detrás de Alcatel, y la cuarta del mundo en fibra óptica.

\section{Gree Electrics Appliances}

Con sede en Zhuai y fundada en 1991, es uno de los primeros fabricantes mundiales de aire acondicionado cuenta con 1.500 modelos, de los que vende cerca de 10 millones de unidades en más de 180 países. La empresa, con una facturación de 1.200 millones de dólares y 15.000 empleados de ellos, más de 1.000 en labores de I+D, añadió recientemente a sus plantas una quinta fábrica en Brasil.

\section{Xiamen Overseas Chinese Electronic}

Es una empresa privada fundada en 1985 en la ciudad de Xiamen. Produce cerca de 15 líneas de productos, desde electrónica de consumo a componentes para telecomunicaciones, factura unos 1.000 millones de euros y actúa en los mercados mundiales con la marca Prima Harwa en Alemania, sobre todo en segmentos bajos, con especial incidencia en el precio. Para cubrir los casi 100 países en los que vende (y a los que exporta el $40 \%$ de su producción) ha creado delegaciones en Alemania, Emiratos Árabes, EE UU, Canadá, Australia y Filipinas y ha construido una planta en Sudáfrica. Cotiza en la Bolsa de Shanghai.

\section{Shanghai Automotive}

Es conocida como una de las`Tres Casadas' por su situación de empresas conjuntas con 11 grandes del automóvil: Volkswagen, GM, etc. Este gigante del automóvil con 50 plantas en Shanghai, de propiedad pública, está expandiéndose internacionalmente. Adquirió en 2003 un 49\% de la coreana Ssangyong Motor, compro los derechos de diseño y desarrollo de MG Rover y negocia 
la compra de la planta de Daewoo en Varsovia. Además, va a lanzar autos con marca propia para el mercado chino e internacional. Produce unas 600.000 unidades al año, prevé un millón en 2006, y es una de las empresas de mayor crecimiento: entre 2001 y 2003 dobló su facturación al alcanzar 11.743 millones de dólares.

\section{Watson}

Una de las primeras cadenas de perfumerías del mundo, con 4.436 establecimientos repartidos por distintos países de Asia y Europa. Es filial del conglomerado Hutchinson Whampoa Limited (HWL), controlado por el multimillonario chino Li Ka-Shing, de 75 años, uno de los hombres más ricos de Asia (según Forbes, su fortuna personal se estima en en 12.400 millones de dólares. Su grupo empresarial, cuyos orígenes datan del siglo XIX, cuenta con más de 100.000 empleados y representa el 11,5\% del total de la capitalización bursátil de la Bolsa de Hong Kong. Está también presente en sectores tan dispares como puertos y servicios portuarios, telecomunicaciones.

\section{Conclusiones.}

Las nuevas multinacionales son el resultado tanto de querer imitar a las multinacionales establecidas de los países ricos-a los que han intentado emular estratégica y organizadamente, como de la innovación en respuesta a las características peculiares de los países emergentes y en vías de desarrollo.

El contexto en el que se ha llevado a cabo su expansión internacional también es relevante. Las nuevas multinacionales también han surgido de países con entornos institucionales débiles, por lo que están acostumbradas a operar en países con regímenes de derechos de propiedad y sistemas 
legales débiles. La experiencia en el país de origen se volvió especialmente valiosa para las nuevas multinacionales porque muchos países con instituciones débiles están creciendo rápidamente y ellas habían desarrollado las capacidades para competir en tales ambientes

En resumen las nuevas multinacionales han prosperado en un momento de globalización de mercado en el que, a pesar de las diferencias locales que todavía permanecen, el alcance y la proporción global son cruciales. Estas empresas han respondido a este reto embarcándose en una estrategia internacional acelerada basada en el crecimiento externo dirigido a aumentar sus capacidades e incrementar su alcance comercial global. Las cuales se aprovecharon de esta estrategia por su posición de mercado en el país de origen y de su escasa presencia internacional, que les permitió adoptar una estrategia y una estructura organizativa, que resultó ser apropiada para el actual escenario internacional.

También es importante destacar que las multinacionales tradicionales han adoptado algunos de los modelos de comportamiento de las nuevas multinacionales. El aumento de presión competitiva de estas últimas en sectores como cemento, acero, electrodomésticos, construcción, banca e infraestructuras ha provocado que muchas empresas norteamericanas y europeas empleen en menor medida estrategias tradicionales de diferenciación de producto y de estructuras integradas verticalmente.

\section{Bibliografía.}

Lascurain Fernández, M. (2012). Empresas multinacionales y sus efectos en los países menos desarrollados. ECONOMÍA: TEORÍA Y PRÁCTICA, 36(1), 83-105.

Martínez Legorreta, O. (2016). La importancia actual y al futuro de la región Asia-Pacífico. México y la cuenca del pacífico, 5(13).

Swan, T. (1956). Economic Growth and Capital Accumulation. Economic Record, 32(1), 334-361. 
Vázquez-Barquero, A. (2000). Desarrollo endógeno y globalización. EURE (Santiago), 29(79).

Waterman, P. (1998). Globalization, Social Movement and the New Internationalism. Londres: Massell/Castells. 